\title{
Intermediate Term Results of Total Hip Arthroplasty with Uncemented Acetabular Components for Patients with a Prior Acetabular Fracture
}

\section{Konigsberg*, Nordin, Lackner, Hartman and Garvin}

University of Nebraska Medical Center, Nebraska Medical Center, USA

*Corresponding Author: Konigsberg, University of Nebraska Medical Center, Nebraska Medical Center, USA.
Received: December 31, 2021

Published: January 25, 2022

(C) All rights are reserved by Konigsberg., et

al.

\section{Abstract}

Background: Acetabulum fractures can lead to post-traumatic arthritis necessitating total hip arthroplasty (THA). Some studies have shown higher rates of failure in patients undergoing THA after acetabular fracture as compared to primary THA. Likewise, studies have shown uncemented acetabular fixation has shown improved outcomes in primary THA.

Study Objective: This study evaluates outcomes of uncemented acetabular fixation in THA for post-traumatic arthritis following an acetabular fracture. Furthermore, there are comparisons of outcomes between highly cross-linked polyethylene (HXLPE) with conventional polyethylene as well as evaluation of outcomes utilizing different femoral head components.

Methods: 78 total hip arthroplasties (77 patients) for post-traumatic arthritis after acetabulum fracture were performed at our institution from 1991-2015. Routine follow-up was performed (range 6 weeks to 23 years). After institutional review board approval, patients were asked to return for clinical and radiographic evaluation. Patients who were unable to return to clinic were contacted by mail and telephone. At the time of this study, twenty-three patients were known to have died. Fifty-eight patients (59 hips) had a minimum of 2 year follow up available.

Results: Of the 78 arthroplasties performed, 8 (10.2\%) underwent revision surgery (3 for instability, 1 for loosening, 1 for wear and trunnionosis, 1 for femoral fracture, 1 for infection, and 1 for persistent pain).

Of the 58 patients with a minimum of 2-year follow-up available, the mean follow-up period was 10.2 years (2-25). 6 of the 59 (10.2\%) arthroplasties has been revised. The mean Harris Hip Score was 79.6 (33-100). There were 50 HXLPE liners, 8 conventional polyethylene and 1 ceramic liner. These showed no clinical or radiographic difference at any follow up period. There was 1 revision for polyethylene wear at 16 years postoperatively in a patient with a conventional liner.

Conclusion: The intermediate term results of a relatively large group of patients who underwent cementless THA for post-traumatic arthritis following acetabular fracture at a single institution over a 24-year period yielded satisfactory outcomes with revision rates comparable or better to other similar studies. Additionally, there were no differences in revision rates seen with conventional polyethylene vs HXPLE. Femoral head implant bearing surface also did not have an observable difference in outcomes.

Keywords: Acetabulum Fracture; Hip Arthroplasties; Posttraumatic Arthritis

\section{Introduction}

Fractures of the acetabulum are uncommon but serious injuries. These fractures often result from high-impact, complex inju- ries and thus have the potential for poor outcomes regardless of how the fracture is initially treated. They can lead to complications such as post-traumatic arthritis, osteonecrosis of the femoral head 
and chondrolysis. Even using the most modern reduction and surgical techniques for fracture management, posttraumatic arthritis has been shown to occur in up to $30 \%$ of patients [1-6]. The posttraumatic arthritis rate continues to remain high due to many factors. Some factors thought to contribute to this high rate include an imperfect reduction of the fracture, acetabular or femoral head osteochondral defects, chondrolysis due to articular trauma at the time of the injury and avascular necrosis of the acetabulum or femoral head [7]. Once a patient with an acetabular fracture develops post-traumatic arthritis treatment options have been limited with total hip arthroplasty remaining the preferred choice for most patients [8].

Patients undergoing total hip arthroplasty (THA) after acetabular fracture are then faced with another challenge. Historically, the results seen in THA after acetabular fractures have been inferior and have led to worse outcomes and higher failure rates than those seen when THA is performed for primary osteoarthritis [9-11]. When compared to primary THA, femoral component complications are similar, but the acetabular component has significantly higher complication rates. Aseptic loosening is thought to be the predominant mode of failure of the acetabular components. THA after acetabular fracture is also more complex than primary THA for degenerative arthritis. This complexity is due to both the technical demands of the surgery and the patient population. Surgical factors contributing to the technical demand of surgery include excessive scarring from previous trauma and/or surgery, presence of fixation hardware, deficient acetabular bone stock, and potential for malunion/nonunion. The patient population in THA after acetabular fracture is also different as compared to those that undergo primary THA for degenerative arthritis. Total hip arthroplasty after acetabular fracture patients are usually younger with a more active lifestyle. This leads to the increased need for the THA components to be more sustainable to account for the increased usage and overall greater longevity needed in these patients $[6,11]$.

It has been known that the use of uncemented acetabular fixation as opposed to cemented fixation has led to improved survivorship in primary THA [12-14]. Studies done by Bellabarba., et al. Berry and Halasy, Huo., et al. and Ranawat., et al. have demonstrated improved results using uncemented acetabular components as opposed to cemented components in THA for post-traumatic arthritis after acetabular fracture $[8,12,15,16]$. In spite of these improved results, THA after acetabular fracture still remains more complicated than primary THA.

\section{Study Objective}

The purpose of this study was to determine and evaluate the intermediate term clinical and radiographic results of a consecutive series of total hip arthroplasties for post-traumatic arthritis following acetabulum fracture with an uncemented acetabular component treated at a single institution. Additionally, a comparison between HXLPE and conventional polyethylene was performed to determine if there was a difference in rate of revision. Finally, the femoral bearing surface was compared to further assess for possible differences in outcomes and need for revision surgery.

\section{Materials and Methods}

A retrospective review found 78 (77 patients) consecutive total hip arthroplasties for post-traumatic arthritis following fracture of the acetabulum at a single institution between 1991-2015. The average age at the time of fracture was 46.0 years (13-84). The average age at time of prosthetic replacement was 51.1 years (1885). Surgeries were performed by 7 different fellowship-trained arthroplasty surgeons. The surgical approach was anterolateral for 6 patients and transtrochanteric for 1 patient. The remaining 71 arthroplasties were performed through a posterior approach. All patients in the series received a cementless acetabular component. In 5 surgeries, advanced acetabular reconstruction techniques with a plate, augment, or revision shell were employed. A fellowship-trained traumatologist assisted with exposure and hardware removal in 4 surgeries. Standard polyethylene liners were placed in 8 patients, while 69 patients had HXLPE liners. Four of the standard polyethylene liners were constrained due to concern for postoperative instability. There was also one patient that the surgeon elected to use a ceramic on ceramic articulation.

Follow-up clinical exams were performed, and radiographs taken for each patient at standard intervals of 6 weeks, 3 months, 1 year, and each subsequent year following. At each follow-up clinical exam, Harris Hip Scores were gathered along with radiographs for each patient. The radiographic series included an anteroposterior pelvis with anteroposterior and cross table lateral views of the respective hip. After institutional review board approval, eligible patients were asked to return to clinic for radiographic and clinical follow up. Patients who were unable to return to clinic were asked to complete a Mayo hip score and a single question survey regarding further surgery on the operative hip. The radiographs were evaluated for evidence of loosening or wear by a group of 3 fellowship trained arthroplasty surgeons as well as a musculoskeletal 
radiologist. The data gathered from the most recent follow-up for each patient was used for the study and the length of follow-up was adjusted accordingly for each patient.

\section{Results}

58 of the 77 patients had 2 year follow up available. The average follow-up for these patients was 10.2 years (2-25). Of the 19 patients without 2 year follow up, 2 were known to have undergone revision surgery. One underwent an explantation for an acute staphylococcal infection at 5 weeks after the index surgery and was recommended not to undergo further surgery due to medical comorbidities. Another patient underwent revision of the femoral stem for a displaced fracture noted on the immediate postoperative radiographs.

Of the patients with a minimum 2 year follow up, 6 (10.3\%) had undergone revision surgery ( 3 for instability, 1 for osteolysis and morse taper corrosion, 1 for persistent pain, and 1 patient with a primary constrained polyethylene liner underwent revision for acetabular loosening). After radiographic review, no other patients were identified with aseptic loosening of their components. Thus, the mechanical failure rate for our cohort was 3.4\%. The mean Harris Hip Score at most recent follow up was 79.6 (SD = 19.2, with a range from 33 to 100 ) at the most recent follow-up for each patient.
Of the 69 HXLPE and 8 conventional polyethylene. Only one patient with conventional polyethylene underwent revision surgery due to polyethylene wear and subsequent osteolysis around the acetabular component. The remainder of the hips showed no evidence of polyethylene wear or appreciable osteolysis at the time of their respective follow up. Furthermore, there was no clinical, radiographic, or observable difference appreciated based on whether a patient had cobalt chrome, ceramic or oxidized zirconium as a femoral bearing surface.

\section{Discussion}

Total hip arthroplasty after an acetabular fracture continues to remain a challenging surgery due to the historically inferior outcomes as compared to THA for non-traumatic arthritis [9-11]. We hypothesized that improved results could be achieved using a cementless acetabular reconstruction and modern surgical techniques.

The results of our study of cementless acetabular reconstruction for the treatment of posttraumatic arthritis after an acetabular fracture were inferior as compared to published results for primary degenerative arthritis but favorable as compared to many prior studies of post-traumatic arthritis. These results are outlined in table 1.

\begin{tabular}{|l|c|c|c|c|c|}
\hline & Acetabular Fixation Method & N & Mean Follow-Up (years) & Failure Rate & HHS \\
\hline Current study & Cementless & 58 & 10.2 & $10 \%$ & 80 \\
\hline Huo., et al. [15] & Cementless & 21 & 5.4 & $19 \%$ & 90 \\
\hline Bellabarba [8] & Cementless & 30 & 6.1 & $3 \%$ & 88 \\
\hline Berry [12] & 44 cemented, 22 cementless & 66 & 9.6 & $29 \%$ & NA \\
\hline Von Roth [17] & Cemented and cementless & 30 & 20 & $21 \%$ & 82 \\
\hline Ranawat [16] & Cementless & 32 & 4.7 & 32 & NA \\
\hline Morison [18] & Cementless & 74 & 10 & $11 \%$ & 89 \\
\hline Wang [19] & Cementless & 33 & 11.5 & 29 & 20 \\
\hline
\end{tabular}

Table 1

Our results confirm that the use cementless acetabular fixation as well as HXLPE does lower the risk of aseptic loosening and polyethylene wear as our mechanical failure rate was only 3.4\%. However, prosthetic instability resulted in another 3 patients requiring revision. Thus, our results suggest that total hip arthroplasty after a prior acetabular fracture is a technically demanding procedure requiring careful attention to ensure not only excellent implant fixation but also appropriate implant stability.

We observed no meaningful difference seen between the use of standard polyethylene and highly crosslinked polyethylene. This contrasts with what has been seen in the contemporary lit- 
erature20. While it is unclear why a larger difference in wear was not seen we hypothesize that it may be related to relatively small patient groups and an overall length of follow-up not adequate to demonstrate a difference.

Not surprisingly, there was also no difference between femoral head bearing surface composition and wear. This was expected as the most recent literature has emphasized that the femoral component ultimately does not appear to dramatically change short-term wear rate [21]. They've demonstrated that the polyethylene liner composition effects wear much more so than the composition of the femoral head, particularly at this time frame.

Our study has several limitations. Firstly, this is a single center study, and, while we are the only academic tertiary care center in our geographic region, it is possible that some patients may have been treated at an outside facility. Secondly, this is a retrospective case series in which patients with asymptomatic loosening may not be detected. Thirdly, although this is the largest sample size of any single center study, the sample size is relatively small.

\section{Conclusion}

Advances in cementless THA after acetabular fracture have led to better clinical and radiographic outcomes and have begun to resemble the outcomes seen in primary non-traumatic THA patients $[8,12,22]$. It is our goal that satisfactory outcome information gathered from our study of a small group of patients who underwent THA for traumatic arthritis after acetabular fracture at a single institution over a 24-year period will continue to help bridge the gap in an otherwise difficult patient population to treat.

\section{Bibliography}

1. Matta JM. "Fracture of the acetabulum: Accuracy of reduction and clinical results in patients managed operatively within three weeks after the injury". Orthopedic Trauma Directions 9.2 (2011): 31-36.

2. Mayo KA. "Open reduction and internal fixation of fractures of the acetabulum. results in 163 fractures". Clinical Orthopaedics and Related Research 305 (1994): 31-37.

3. Letournel E. "Acetabulum fractures: Classification and management". Orthopedic Trauma Directions 5.5 (2007): 27-33.

4. Pennal GF., et al. "Results of treatment of acetabular fractures". Clinical Orthopaedics and Related Research 151 (1980): 115123.
5. Ragnarsson B and Mjöberg B. "Arthrosis after surgically treated acetabular fractures: A retrospective study of 60 cases". Acta Orthopaedica Scandinavica 63.5 (1992): 511-514.

6. Frietman B., et al. "Patient-reported outcome measures after surgery for an acetabular fracture". Bone Joint Journal 100.5 (2018): 640-645.

7. Jimenez ML., et al. "Total hip replacement after acetabular fracture”. Orthopedic Clinics 28.3 (1997): 435-446.

8. Bellabarba C., et al. "Cementless acetabular reconstruction after acetabular fracture". Journal of Bone and Joint Surgery 83.6 (2001): 868-876.

9. Malkin C and Tauber C. "Total hip arthroplasty and acetabular bone grafting for unreduced fracture-dislocation of the hip". Clinical Orthopaedics and Related Research 1985 (201): 57-59.

10. Rogan IM., et al. "Total hip-replacement following fracture dislocation of the acetabulum" 61.2 (1979): 252.

11. Romness DW and Lewallen DG. "Total hip arthroplasty after fracture of the acetabulum. long-term results". The Journal of Bone and Joint Surgery. British Volume 72.5 (1990): 761-764.

12. Berry DJ and Halasy M. "Uncemented acetabular components for arthritis after acetabular fracture". Clinical Orthopaedics and Related Research $₫ 405$ (2002): 164-167.

13. Berger RA., et al. "Hybrid total hip arthroplasty: 7-to 10year results". Clinical Orthopaedics and Related Research 333 (1996): 134-146.

14. Mohler CG., et al. "Total hip replacement with insertion of an acetabular component without cement and a femoral component with cement. four to seven-year results". The Journal of Bone and Joint Surgery. American Volume 77.1 (1995): 86-96.

15. Huo MH., et al. "Total hip replacements done without cement after acetabular fractures: A 4-to 8-year follow-up study". Journal of Arthroplasty 14.7 (1999): 827-831.

16. Ranawat A., et al. "Total hip arthroplasty for posttraumatic arthritis after acetabular fracture". Journal of Arthroplasty 24.5 (2009): 759-767.

17. Von Roth P., et al. "Total hip arthroplasty after operatively treated acetabular fracture: A concise follow-up, at a mean of twenty years, of a previous report". Journal of Bone and Joint Surgery 97.4 (2015): 288-291. 
18. Morison Z., et al. "Total hip arthroplasty after acetabular fracture is associated with lower survivorship and more complications". Clinical Orthopaedics and Related Research ${ }^{\circledR} 474.2$ (2016): 392-398.

19. Wang T., et al. "Delayed total hip arthroplasty after failed treatment of acetabular fractures: An 8-to 17-year follow-up study". Journal of Orthopaedic Surgery and Research 13.1 (2018): 1-7.

20. Surace MF., et al. "Conventional versus cross-linked polyethylene for total hip arthroplasty". Orthopedics 38.9 (2015): 556561.

21. Jassim SS., et al. "Five-year comparison of wear using oxidised zirconium and cobalt-chrome femoral heads in total hip arthroplasty: A multicentre randomised controlled trial". The Bone and Joint Journal 97.7 (2015): 883-889.

22. Weber M., et al. "Total hip arthroplasty after operative treatment of an acetabular fracture". Journal of Bone and Joint Surgery 80.9 (1998): 1295-1305.

\section{Assets from publication with us}

- Prompt Acknowledgement after receiving the article

- Thorough Double blinded peer review

- Rapid Publication

- Issue of Publication Certificate

- High visibility of your Published work

Website: www.actascientific.com/

Submit Article: www.actascientific.com/submission.php

Email us: editor@actascientific.com

Contact us: +919182824667 